\title{
Analisis Produktivitas Alat Berat Pada Pekerjaan Timbunan
}

\author{
Dian Febrianti* ${ }^{1}$, Zulyaden $^{2}$ \\ ${ }^{1,2}$ Jurusan Teknik Sipil, Fakultas Teknik, Universitas Teuku Umar, Alue Penyareng Meulaboh 23615 \\ e-mail: ${ }^{* 1}$ dianfebrianti_heri@yahoo.co.id, ${ }^{2}$ zulyaden@utu.ac.id
}

\begin{abstract}
Abstrak
Alat berat memegang peranan penting dalam hal kecepatan dan percepatan pekerjaan. Proyek peningkatan jalan alun-alun Suka Makmue-jalan lingkar timur ibu kota tahap II, dana yang bersumber dari anggaran OTSUS Kabupaten Nagan Raya dengan biaya proyek Rp.3.922.503.000,- panjang jalan 2475 m. Pekerjaan yang diikuti adalah pekerjaan timbunan pilihan, lapisan pondasi agregat kelas B, lapisan pondasi agregat kelas A. Penelitian ini menggunakan alat berat dump truck, motor grader, vibrator roller, water tanker truck. Tujuan penelitian ini untuk mengetahui produktivitas kerja alat berat dan mengetahui waktu yang dibutuhkan alat berat untuk menyelesaikan pekerjaan. Metode yang digunakan adalah metode perhitungan secara manual dengan menggunakan rumus produktivitas. Berdasarkan hasil perhitungan produktivitas pada pekerjaan timbunan pilihan menggunakan dump truck produksi perjam 32,4 $\mathrm{m}^{3} / \mathrm{jam}$, produksi per hari 259,2 $\mathrm{m}^{3}$ /hari dengan waktu 11 hari, 6 hari pekerjaan lapisan agregat kelas B, 4 hari pekerjaan lapisan agregat kelas A, motor grader produksi perjam 128,3 $\mathrm{m}^{3} / \mathrm{jam}$, produksi per hari 1026,43 $\mathrm{m}^{3} /$ hari dengan waktu 3 hari, 2 hari pekerjaan lapisan agregat kelas B, 1 hari pekerjaan lapisan agregat kelas A, vibrator roller produksi perjam $64,8 \mathrm{~m}^{3} / \mathrm{jam}$, produksi per hari 518,4 $\mathrm{m}^{3}$ /hari dengan waktu 6 hari, 3 hari pekerjaan lapisan agregat kelas B, 2 hari pekerjaan lapisan agregat kelas A, water tanker truck produksi perjam 16,2 $\mathrm{m}^{3} /$ jam, produksi per hari 129,6 $\mathrm{m}^{3}$ /hari dengan waktu 21 hari, 11 hari pekerjaan lapisan agregat kelas B, 8 hari pekerjaan lapisan agregat kelas $A$.
\end{abstract}

Kata kunci-produktivitas, alat berat, waktu pekerjaan.

\begin{abstract}
Heavy equipment plays an important role in terms of speed and acceleration of work. The road improvement project of Suka Makmue Square - the eastern ring road of capital of phase II, funding from OTSUS budget of Nagan Raya Regency with project cost Rp.3.922.503.000, - road length $2475 \mathrm{~m}$ The work followed is preferred heap work, B-class aggregate foundation layers, class A aggregate foundation layers. This research uses heavy equipment dump trucks, motor graders, roller vibrators, water tanker trucks. The purpose of the research is to know the productivity of heavy equipment and to know the time needed by heavy equipment to complete the work. The method used is the calculation method manually using the formula productivity. Based on the calculation of productivity at occupation of accumulation using dump truck production per hour 32,4 m/hour, production per day $259.2 \mathrm{~m} /$ day with 11 days, 6 days class $B$ class aggregate work, 4 days class A class aggregate work, motor grader production hourly 128,3 $\mathrm{m} /$ hour, production per day 1026,43 m3/day with time 3 day, 2 days class B class aggregate work, 1 day class A class aggregate work, vibrator roller production hourly 64,8 m3/hour, production per day 518,4 m3/day with time 6 days, 3 days class aggregate layer work B , 2 days class A class aggregate work, water tankers truck production per hour $16.2 \mathrm{m3/hour,} \mathrm{production} \mathrm{per} \mathrm{day} \mathrm{129,6} \mathrm{m3/day} \mathrm{with} 21$ days, 11 days class $B$ aggregate work, 8 days class A class aggregate work
\end{abstract}

Keywords-productivity, heavy equipment, time of work. 


\section{PENDAHULUAN}

$\mathrm{P}$ erkembangan sarana transportasi pada saat ini sudah sangat pesat dan mempunyai peran penting terutama yang menyangkut perwujudan perkembangan antar daerah yang seimbang dan pemerataan hasil pembangunan dalam bidang ekonomi, politik, sosial, budaya dan pertahan keamanan. Karena jalan mempunyai peranan yang sangat penting, maka pemerintah mempunyai hak dan kewajiban pembinaan jaringan jalan dengan cara melakukan perencanaan, pemeliharaan, serta pengelolaan sebagaimana mestinya.

Proyek yang secara umum dapat didefinisikan sebagai kegiatan spesifik yang dibatasi oleh waktu, sumber daya manusia, alat, material dan uang, dengan adanya alat sangatlah terbantu, dimana proyek yang waktunya sangat terbatas dan dipercepat pelaksanaannya.

Pemakaian alat berat sangatlah diperlukan dalam proses mempercepat pelaksanaan pekerjaan peningkatan jalan sesuai dengan target yang telah ditentukan. Untuk itu dibutuhkan analisis produktivitas peralatan pada suatu proyek yang akan sangat membantu dalam penentuan waktu kerja peralatan, sehingga mengakibatkan efektifnya sumber daya, baik sumber daya peralatan itu sendiri maupun sumber daya lainnya agar kegiatan tersebut bisa selesai sesuai dengan waktu yang direncanakan. Alat berat didalam proyek konstruksi memegang peranan sangat penting, oleh karena itu pemahaman akan jenis-jenis alat berat sangat diperlukan terutama pada tahap perencanaan, karena alat berat yang dipilih harus sesuai dengan kebutuhan proyek.

Proyek Peningkatan Jalan Alun-Alun Suka Makmue-Jalan Lingkar Timur Ibu Kota Tahap II, dana bersumber dari anggaran OTSUS Kabupaten Nagan Raya tahun anggaran 2017 dengan biaya proyek Rp.3.922.503.000,- (tiga miliyar sembilan ratus dua puluh dua juta lima ratus tiga ribu rupiah) dengan panjang jalan $2475 \mathrm{~m}$. Pelaksana proyek ini adalah PT. Adik Abang Qanita Pratama, perencana proyek adalah CV. Neufert Consultant, dan pengawas proyek adalah CV. Neufert Consultant.

Berdasarkan latar belakang yang telah diuraikan, maka tujuan dari penelitian ini adalah untuk mengetahui jenis alat berat yang digunakan pada proyek peningkatan jalan alun-alun suka makmue-jalan lingkar timur ibu kota tahap II, dan mengetahui produktivitas kerja alat berat yang digunakan pada pekerjaan timbunan, lapisan pondasi agregat kelas B, lapisan pondasi agregat kelas A.

Batasan masalah pada penelitian ini adalah hanya meninjau alat berat yang digunakan pada pekerjaan timbunan pilihan, lapisan pondasi agregat kelas B, lapisan pondasi agregat kelas A, alat berat yang digunakan adalah, dump truck, motor grader, vibrator roller, water tanker truck, peneltian ini dimulai dari Sta 0+00 sampai Sta 1+100 dari total panjang jalan $2475 \mathrm{~m}$, Jam kerja dimulai dari pagi jam 08.00 WIB dan berakhir pada sore jam 18.00 WIB ( 8 jam kerja efektif).

Manfaat dari penelitian ini adalah dapat memberikan sumbangan pemikiran bagi pihak perencana dalam merencanakan anggaran biaya berdasarkan produktivitas alat berat sehingga dapat mengoptimalkan dalam pengendalian waktu pekerjaan, sebagai bahan referensi. sedangkan bagai peneliti, penelitian tentang produktivitas alat berat pada sebuah proyek bertujuan untuk menambah wawasan kepada peneliti tentang produktivitas alat berat.

\section{TINJAUAN KEPUSTAKAAN}

Sifat tanah menurut Rochmanhadi (1982), material tanah (soil) tidak mempunyai sifat yang benar-benar khas, berbeda sekali dengan beton dan baja. Material tanah di alam terdiri dari dua bagian yaitu bagian padat terdiri dari partikel-partikel material tanah yang padat, sedangkan bagian pori berisi air dan udara. Sifat-sifat fisik material tanah juga perlu diketahui, tetapi yang penting disini adalah keadaan material tanah yang dapat berpengaruh terhadap volume tanah yang dijumpai dalam usaha pemindahan tanah yaitu keadaan asli sebelum diadakan pekerjaan, keadaan lepas dan 
keadaan padat. Selain keadaan tersebut diatas, menurut Rochmanhadi (1982) perlu diketahui pula faktor tanah yang dapat mempengaruhi produktivitas alat berat antara lain :

- Berat material adalah berat tanah dalam keadaan asli atau lepas pada suatu volume tertentu $\left(\operatorname{ton} / \mathrm{m}^{3}\right)$. Berat material ini akan berpengaruh terhadap volume yang diangkut/didorong, berhubungan dengan draw bar pull (DBP) atau tenaga tarik.

- Kekerasan tanah yang lebih keras akan lebih sukar untuk dikerjakan oleh suatu alat, sehingga kekerasan tanah ini berpengaruh terhadap produktivitas alat. Oleh karenanya diperlukan pengukuran kekerasan jalan.

- Daya ikat/kohesivitas Merupakan kemampuan untuk saling mengikat diantara butir tanah itu sendiri, sifat ini berpengaruh terhadap alat misalnya pengaruh terhadap spillage factor (faktor luber).

- Bentuk material yang dimaksudkan disini didasarkan pada ukuran butir kecil akan terdapat rongga yang berukuran kecil pula, demikian pula pada tanah dengan ukuran besar akan membentuk rongga yang besar. Ukuran butir berpengaruh terhadap terhadap pengisian bucket, dengan mengingat kapasitas munjung dan rongga tanah yang ada dalam bucket. Konvensi juga perlu dilakukan terhadap pengembangan (swelling) dan penyusutan (shrinkage) material tersebut.

Menurut Wilopo (2011), manajemen pemilihan dan pengendalian alat berat adalah proses merencanakan, mengorganisir, memimpin dan mengendalikan alat berat untuk mencapai tujuan pekerjaan yang ditentukan, beberapa faktor yang harus diperhatikan dalam pemilihan alat berat, sehingga kesalahan dalam pemilihan alat dapat dihindari antara lain adalah

- fungsi yang harus dilaksanakan, Alat berat dikelompokkan berdasarkan fungsinya, seperti untuk menggali, mengangkut, meratakan permukaan;

- Kapasitas peralatan. Pemilihan alat berat didasarkan pada volume total atau berat material yang harus dikerjakan. Kapasitas alat yang dipilh harus sesuai sehingga pekerjaan dapat diselesaikan pada waktu yang ditentukan;

- Cara operasi. Alat berat dipilih berdasarkan arah (horizontal maupun vertikal) dan jarak gerakan, kecepatan, frekuensi gerakan;

- Pembatasan dari metode yang dipakai. Pembatasan yang mempengaruhi pemilihan alat berat antara lain peraturan lalu lintas, biaya, dan pembongkaran. Selain itu metode konstruksi yang dipakai dapat membuat pemilihan alat dapat berubah;

- Ekonomi. Selain biaya investasi atau biaya sewa peralatan, biaya operasi dan pemeliharaan merupakan faktor penting didalam peilihan alat berat.

- Jenis proyek. Ada beberapa jenis proyek yang umumnya menggunakan alat berat. Proyekproyek tersebut antara lain proyek gedung, pelabuhan, jalan, jembatan, irigasi, dan pembukaan hutan;

- Lokasi proyek. Lokasi proyek juga merupakan hal lain yang perlu diperhatikan dalam pemilihan alat berat. Sebagai contoh lokasi didataran tinggi memerlukan alat berat yang berbeda dengan lokasi proyek didataran rendah;

- Jenis dan daya dukung tanah. Jenis tanah dilokasi proyek dan jenis material yang akan dikerjakan dapat mempengaruhi alat berat yang akan dipakai. Tanah dapat dalam kondisi padat, lepas, keras atau lembek;

- Kondisi lapangan. Kondisi dengan medan yang sulit dan medan yang baik merupakan faktor lain yang mempengaruhi pemilihan alat berat.

Produktivitas didefinisikan sebagai rasio antara out put dengan input, atau rasio antara hasil produksi dengan total sumber daya yang digunakan. Dalam proyek konstruksi, rasio produktivitas adalah nilai yang diukur selama proses konstruksi, dapat dipisahkan menjadi biaya tenaga kerja, material, uang, metoda dan alat. Sukses dan tidaknya proyek konstruksi tergantung pada efektifitas pengelolaan sumber daya. Sebuah sistem umumnya dibutuhkan "sesuatu" yang berfungsi 
menjalankannya, yaitu organisasi. Efektivitas organisasi merupakan modal utama untuk menggerakkan subsistem yang ada didalamnya. Faktor manusia menjadi penentu untuk mencapai tingkat produktivitas yang ditetapkan. Untuk mendapatkan tingkat produktivitas yang diinginkan dan meminimalkan segala resiko yang mungkin terjadi serta mengutamakan keselamatan dan kesehatan kerja, para pimpinan harus memahami kemampuan dan keterbatasan yang diakibatkan oleh kondisi lokasi proyek (Ervianto; 2003), produktivitas adalah kemampuan alat dalam satuan waktu $\left(\mathrm{m}^{3} / \mathrm{jam}\right)$, dan alat berat merupakan faktor penting didalam proyek terutama proyek-proyek konstruksi dengan skala yang besar. Tujuan penggunaan alat-alat berat tersebut untuk memudahkan manusia dalam mengerjakan pekerjaannya sehingga hasil yang diharapkan bisa tercapai dengan lebih mudah dengan waktu yang relatif singkat. Produktivitas alat tergantung pada kapasitas, waktu siklus alat, dan efisiensi alat. Siklus kerja dalam pemindahan material merupakan suatu kegiatan yang dilakukan berulang Waktu yang diperlukan dalam siklus kegiatan diatas disebut waktu siklus. Waktu siklus sendiri terdiri dari beberapa unsur, waktu yang diperlukan di dalam siklus kegiatan disebut waktu siklus atau Cycle Time (CT).

Waktu muat merupakan waktu yang dibutuhkan oleh suatu alat untuk memuat material ke dalam alat angkut sesuai dengan kapasitas alat angkut tersebut. Kemudian waktu angkut atau Hauling Time (HT), waktu angkut merupakan waktu yang diperlukan oleh suatu alat untuk bergerak dari tempat permuatan ke tempat pembongkaran. Waktu angkut tergantung dari jarak angkut, kondisi jalan, tenaga alat, dan lain-lain. Pada saat kembali ke tempat permuatan maka waktu yang diperlukan untuk kembali disebut (Return Time). Waktu kembali lebih singkat daripada waktu berangkat karena kendaraan dalam keadaan tidak ada muatan (Rostiyanti; 1999).

Menurut Rochmanhadi (1982), produktivitas alat berat pada kenyataan dilapangan tidak sama jika dibandingkan dengan kondisi ideal alat dikarenakan hal-hal tertentu seperti topografi, keahlian operator, pengoperasian dan pemeliharaan alat. Produktivitas per jam alat yang harus diperhitungkan dalam perencanaan adalah produktivitas standart alat pada kondisi ideal dikalikan suatu faktor yang disebut efisiensi kerja. Besarnya nilai efisiensi kerja ini sulit ditentukan secara tepat tetapi berdasarkan pengalaman-pengalaman dapat ditentukan efisiensi kerja yang mendekati kenyataan. Efektivitas alat tersebut bekerja tergantung dari beberapa hal yaitu :

- Kemampuan operator pemakai alat;

- Pemilihan dan pemeliharaan alat;

- Perencanaan dan pengaturan letak alat;

- Topografi dan volume pekerjaan;

- Kondisi cuaca;

- Metode pelaksanaan alat.

Nilai efisiensi kerja alat berat dapat dilihat dari kondisi operasi alat berat yang digunakan pada proyek pekerjaan. Nilai-nilai efisiensi kondisi operasi alat berat digunakan untuk menghitung produktivitas sebuah alat berat.

\section{Jenis alat berat yang digunakan}

a. Dump truck

Menurut Rochmanhadi (1982), dump truck adalah suatu alat yang berfungsi memindahkan suatu material dari suatu tempat ke tempat lain. Untuk menghitung produktivitasnya digunakan rumus sebagai berikut :

$$
P=\frac{C \times 60 \mathrm{Et}}{\mathrm{Cmc}} \mathrm{xM}
$$

Dimana :

$\mathrm{P} \quad=$ Produksi per jam $\left(\mathrm{m}^{3} / \mathrm{jam}\right)$; 
Vol. 3 No.4 April 2017

pp. $21-30$

$\mathrm{M} \quad=$ Jumlah dump truck;

$\mathrm{Cmc}=$ Waktu siklus dump truck;

$\mathrm{C}=$ Produksi per siklus;

Et $\quad=$ Efisiensi kerja alat.

b. Motor grader

Menurut Rochmanhadi (1982), motor grader adalah suatu sarana (angkut) rancang-bangun dengan suatu mata pisau besar yang digunakan untuk menciptakan sebuah permukaan datar. Untuk menghitung produktivitasnya digunakan rumus sebagai berikut :

$Q_{A}=V \times(L e-L o) \times 1000 \times E$

Dimana :

$\mathrm{Q}_{\mathrm{A}} \quad=$ Produksi per jam $\left(\mathrm{m}^{3} / \mathrm{jam}\right)$;

Le = Panjang efektif blade;

$\mathrm{V} \quad=$ Kecepatan kerja $(\mathrm{km} / \mathrm{jam})$;

Lo = Tebal penghamparan $(\mathrm{cm})$;

Et $\quad=$ Efisiensi kerja alat.

c. Vibrator roller

Menurut Rochmanhadi (1982), vibrator roller adalah alat berat yang digunakan untuk menggilas, memadatkan hasil timbunan, sehingga kepadatan tanah yang dihasilkan lebih sempurna. Untuk menghitung produktivitasnya digunakan rumus sebagai berikut :

$$
\mathrm{P}=\frac{(\mathrm{V} \times 1000) \times \mathrm{B} \times \mathrm{T} \times \mathrm{E}}{\mathrm{N}}
$$

Dimana :

$\mathrm{P} \quad=$ Produksi per jam $\left(\mathrm{m}^{3} / \mathrm{jam}\right)$;

$\mathrm{B} \quad=$ Diameter drum $(\mathrm{m})$;

$\mathrm{V}=$ Kecepatan operasi alat $(\mathrm{km} / \mathrm{jam})$;

$\mathrm{T}=$ Tebal pemadatan;

Et $\quad=$ Efisiensi kerja alat;

$\mathrm{N}=$ Jumlah lintasan.

d. Water tanker truck

Menurut Rochmanhadi (1982), water tanker truck adalah kendaraan berat yang dirancang untuk membawa air, menyiram permukaan material yang dipadatkan. Untuk menghitung produktivitasnya digunakan rumus sebagai berikut :

$$
\mathrm{Q}=\frac{\mathrm{C} \times \mathrm{n} \times \mathrm{E}}{\mathrm{Wc}}
$$

Dimana :

$\mathrm{Q}=$ Produksi per jam $\left(\mathrm{m}^{3} / \mathrm{jam}\right)$;

$\mathrm{n} \quad=$ Pengisian tangki per jam $\left(\mathrm{m}^{3} / \mathrm{jam}\right) ;$

$\mathrm{C}=$ Kapasitas bak $\left(\mathrm{m}^{3}\right)$;

$\mathrm{Wc}=$ Kebutuhan air;

Et $=$ Efisiensi kerja alat. 


\section{Volume pekerjaan}

Volume suatu pekerjaan adalah menghitung jumlah banyaknya volume pekerjaan dalam satu satuan. Volume juga disebut sebagai kubikasi pekerjaan. Untuk menghitung volume masing-masing pekerjaan digunakan rumus sebagai berikut;

\section{Volume $=p \times l \times t$}

Dimana :

$\mathrm{p}=$ Panjang $(\mathrm{m})$

1 = Lebar $(\mathrm{m})$;

$\mathrm{t}=$ Tinggi $(\mathrm{m})$

\section{Waktu pemakaian alat berat}

Menghitung produktivitas dari masing-masing alat berat dan volume dari tiap-tiap pekerjaan sangatlah diperlukan untuk dapat menghitung waktu pemakaian alat berat. Rumus yang digunakan untuk menghitung waktu pemakaian alat berat adalah sebagai berikut:

Waktu pemakaian alat berat $=\frac{\text { Volume Pekerjaan }}{\text { Produktivitas Alat Berat }}$

\section{METODE PENELITIAN}

Metodologi penelitian adalah langkah-langkah dan rencana dari proses berfikir dan memecahkan masalah yang dimulai dari perumusan masalah, pengamatan, pengumpulan data baik dari referensi tertulis maupun observasi langsung dilapangan. Melakukan pengolahan dan interprestasi data sampai penarikan kesimpulan atas permasalahan yang diteliti.

Tahapan metode penelitian ini dimulai dengan mengumpulkan data-data yang ada di studi kasus, selanjutnya dilakukan persiapan untuk mendapatkan tahapan informasi dengan mengumpulkan data primer dan data sekunder. Setelah data-data terkumpul maka dilakukan pengolahan data.

Penelitian ini dilakukan di Jalan Tgk. H. Zakaria Yunus Kecamatan Suka Makmue Kabupaten Nagan Raya pada proyek peningkatan jalan Alun-Alun Suka Makmue-Jalan Lingkar Timur Ibu Kota Tahap II.

Pengumpulan data merupakan faktor penting demi keberhasilan penelitian. Metode pengumpulan data merupakan teknik atau cara yang dilakukan untuk mengumpulkan data. Pengumpulan data dilakukan untuk memperoleh hasil informasi yang dibutuhkan dalam rangka mencapai tujuan penelitian. Data yang diperoleh pada penelitian ini terdiri dari data primer dan data sekunder.

Data primer adalah data yang dikumpulkan ataupun diperoleh langsung dilapangan dengan melihat langsung dan wawancara dengan pekerja dan kontraktor. Tujuan dari pengambilan data primer adalah untuk mencari data yang sifatnya realitatif pelaksanaan pekerjaan lapangan. Pada penelitian ini yang merupakan data primer adalah waktu pemakaian alat berat dan jenis alat berat. Data yang diperoleh dari hasil pengamatan itu akan digunakan untuk menghitung produktivitas alat berat.

Data sekunder adalah data penunjang yang dikumpulkan melalui studi kepustakaan, hasil penelitian terdahulu data dan lain sebagainya. Tujuan dari pengumpulan data sekunder ini adalah untuk mendapatkan data instansional yang selanjutnya akan diolah dan dianalisa. Pada penelitian ini yang merupakan data sekunder adalah dokumen kontrak, shop drawing dan foto-foto alat berat. 
Semua data yang didapat dari hasil pengamatan dilapangan berupa data primer digunakan sebagai acuan dalam analisis produktivitas alat berat. Pengolahan data dilakukan secara manual dengan bantuan microsoft office excel berdasarkan teori-teori dengan menggunakan rumus-rumus persamaan produktivitas serta hasil pengamatan langsung dilapangan dan akan disesuaikan dengan kondisi-kondisi yang didapatkan dilapangan.

\section{HASIL DAN PEMBAHASAN}

Hasil yang didapat pada penelitian ini berupa produktivitas alat berat dan waktu keseluruhan pemakaian alat berat untuk menyelesaikan pekerjaan timbunan pilihan, lapisan pondasi agregat kelas B, lapisan pondasi agregat A pada Proyek Peningkatan Jalan Alun-Alun Suka Makmue-Jalan Lingkar Timur Ibu Kota (Tahap II).

Untuk mendapatkan hasil dari penelitian maka akan dilakukan beberapa perhitungan sebagai berikut :

\section{Perhitungan produktivitas alat berat}

Penggunaan alat berat yang tepat dengan kondisi dan situasi lapangan pekerjaan akan berpengaruh pada kerugian nilai produksi dan tidak tercapainya jadwal atau target yang telah ditentukan. Dalam penelitian ini akan dibahas beberapa perhitungan produksi alat berat yang digunakan pada pekerjaan galian, timbunan pilihan, lapisan pondasi agregat kelas B, lapisan pondasi agregat A. Alat-alat berat yang diteliti adalah excavator, dump truck, motor grader, vibrator roller dan water tanker truck.

Jumlah perhitungan produktivitas alat berat yang didapat berdasarkan pekerjaan yang diikuti adalah sebagai berikut : kelas A

Pekerjaan timbunan pilihan, pekerjaan lapisan agregat kelas B dan Pekerjaan lapisan agregat

- $\quad$ Dump truck

$$
\begin{aligned}
& \text { - } \text { Produksi } / \mathrm{jam}=32,4 \mathrm{~m}^{3} / \mathrm{jam} \\
& \text { - } \text { Produksi/hari }=259,2 \mathrm{~m}^{3} / \text { hari } \\
& \text { - } \quad \text { Motor grader } \\
& \text { - Produksi } / \mathrm{jam}=128,3 \mathrm{~m}^{3} / \mathrm{jam} \\
& \text { - } \text { Produksi } / \text { hari }=1026,43 \mathrm{~m}^{3} / \text { hari } \\
& \text { - Vibrator roller } \\
& \text { - Produksi/jam }=64,8 \mathrm{~m}^{3} / \mathrm{jam} \\
& \text { - Produksi } / \text { hari }=518,4 \mathrm{~m}^{3} / \text { hari } \\
& \text { - Water tanker truck } \\
& \text { - } \text { Produksi } / \mathrm{jam}=16,2 \mathrm{~m}^{3} / \mathrm{jam} \\
& \text { - } \text { Produksi/hari }=129,6 \mathrm{~m}^{3} / \text { hari }
\end{aligned}
$$

\section{Perhitungan volume dan waktu pemakaian alat.}

Proses pekerjaan timbunan material membutuhkan beberapa alat berat untuk menunjang efektivitas pekerjaan, dari masing-masing alat berat memiliki tipe dan waktu kerja, dimana antara tipe satu dengan tipe yang lain memiliki kapasitas waktu yang berbeda-beda. Untuk menghitung waktu pemakaian alat berat, perlu diketahui volume dari pekerjaan pekerjaan timbunan.

Adapun jumlah perhitungan volume dan waktu alat berat adalah sebagai berikut :

a. Perhitungan volume pekerjaan

- Volume timbunan pilihan $\quad=2640 \mathrm{~m}^{3}$

- Volume lapisan agregat kelas B $\quad=1320 \mathrm{~m}^{3}$ 
- Volume lapisan agregat kelas A $\quad=990 \mathrm{~m}^{3}$

b. Perhitungan waktu pemakaian alat berat

- Pekerjaan Timbunan Pilihan

Dump truck Mitshubishi 120 PS

- Lama waktu pekerjaan

Motor grader Komatsu GD 605 A

- Lama waktu pekerjaan = 3 hari

Vibrator roller STR D-100 D

- Lama waktu pekerjaan $\quad=6$ hari

Water tanker truck Mitshubishi 120 PS

- Lama waktu pekerjaan = 21 hari

- Pekerjaan Lapisan Agregat Kelas B

Dump truck Mitshubishi 120 PS

- Lama waktu pekerjaan

- Lama waktu pekerjaan $\quad=2$ hari

Vibrator roller STR D-100 D

- Lama waktu pekerjaan $\quad=3$ hari

Water tanker truck Mitshubishi 120 PS

- Lama waktu pekerjaan = 11 hari

- Pekerjaan Lapisan Agregat Kelas A

Dump truck Mitshubishi 120 PS

- Lama waktu pekerjaan = 4 hari

Motor grader Komatsu GD 605 A

- Lama waktu pekerjaan = 1 hari

Vibrator roller STR D-100 D

- Lama waktu pekerjaan $\quad=2$ hari

Water tanker truck Mitshubishi 120 PS

- Lama waktu pekerjaan $\quad=8$ hari

Proyek yang menjadi pembahasan dalam penelitian ini adalah peningkatan jalan alun-alun Suka Makmue-jalan lingkar timur ibu kota tahap II kabupaten Nagan Raya, yang terdiri atas pekerjaan timbunan pilihan, lapisan agregat kelas B dan lapisan agregat kelas A, dimulai dari Sta 0+00 sampai Sta 1+100 dengan panjang jalan $2475 \mathrm{~m}$, pada pekerjaan ini alat berat yang ditinjau adalah dump truck, motor grader, vibrator roller dan water tanker truck.

Setelah melakukan penelitian dan mendapatkan data yang dibutuhkan untuk mendapatkan hasil penelitian, maka dengan menggunakan metode perhitungan secara manual dapat dihitung produktivitas alat berdasarkan rumus-rumus persamaan dan menghitung waktu pemakaian alat berat dengan mengetahui volume dari tiap-tiap pekerjaan yang diikuti.

Pekerjaan timbunan pilihan menggunakan alat berat dump truck untuk mengangkut material, produktivitas yang didapat adalah $32,4 \mathrm{~m}^{3} / \mathrm{jam}$, sedangkan produksi 1 hari dengan 8 jam kerja efektif adalah $259,2 \mathrm{~m}^{3} /$ hari, dengan volume pekerjaan timbunan pilihan $2640 \mathrm{~m}^{3}$ maka waktu pemakaian dump truck adalah selama 11 hari. Setelah agregat ditumpukkan kemudian dilakukan penghamparan dengan menggunakan motor grader. Produktivitas motor grader yang didapat adalah 128,3 $\mathrm{m}^{3} / \mathrm{jam}$, produksi 1 hari dengan 8 jam kerja efektif adalah 1026,43 $\mathrm{m}^{3} /$ hari, dengan volume pekerjaan timbunan pilihan $2640 \mathrm{~m}^{3}$ maka waktu pemakaian motor grader adalah selama 3 hari. Setelah dihamparkan oleh motor grader kemudian dipadatkan dengan vibrator roller. Produktivitas vibrator roller yang didapat adalah $64,8 \mathrm{~m}^{3} / \mathrm{jam}$, sedangkan produksi 1 hari dengan 8 jam kerja efektif adalah $518,4 \mathrm{~m}^{3} /$ hari, dengan volume pekerjaan timbunan pilihan 2640 $\mathrm{m}^{3}$ maka waktu pemakaian motor grader adalah selama 6 hari. Setelah dipadatkan kemudian 
disiramkan air menggunakan water tanker truck ke atas permukaan material kemudian dipadatkan kembali. Produktivitas water tanker truck yang didapatkan adalah $16,2 \mathrm{~m}^{3} / \mathrm{jam}$, produksi 1 hari dengan 8 jam kerja efektif adalah 129,6 $\mathrm{m}^{3} /$ hari, dengan volume pekerjaan timbunan pilihan 2640 $\mathrm{m}^{3}$ maka waktu pemakaian water tanker truck adalah selama 21 hari. Pada pekerjaan lapisan agregat kelas B menggunakan alat berat dump truck, motor grader, vibrator roller, water tanker truck, dengan produktivitas yang sama, volume pekerjaan lapisan agregat kelas B adalah $1320 \mathrm{~m}^{3}$ maka waktu pemakaian dump truck adalah selama 6 hari, waktu pemakaian motor grader adalah selama 2 hari, waktu pemakaian vibrator roller adalah selama 3 hari dan waktu pemakaian water tanker truck adalah selama 11 hari. Pada pekerjaan lapisan agregat kelas A menggunakan alat berat dump truck, motor grader, vibrator roller, water tanker truck, dengan produktivitas yang sama, volume pekerjaan lapisan agregat kelas A adalah $990 \mathrm{~m}^{3}$ maka waktu pemakaian dump truck adalah selama 4 hari, waktu pemakaian motor grader adalah selama 1 hari, waktu pemakaian vibrator roller adalah selama 2 hari dan waktu pemakaian water tanker truck adalah selama 8 hari.

Berdasarkan hasil perhitungan analisis produktivitas alat berat yang didapat, maka dapat disimpulkan bahwa jenis alat berat yang akan digunakan sangat berpengaruh terhadap proses pelaksanaan pekerjaan. Pemakaian alat berat yang bagus pada sebuah proyek akan sangat membantu proses pelaksanaan pekerjaan selesai tepat pada waktunya.

Pemilihan alat berat dilakukan pada tahap perencanaan untuk setiap jenis, jumlah dan kapasitas alat merupakan faktor-faktor penentu. Tidak semua alat berat dapat dipakai untuk proyek konstruksi, oleh karena itu pemilihan alat berat yang tepat sangatlah diperlukan, apabila kesalahan dalam pemilihan alat berat maka akan terjadi keterlambatan dalam pelaksanaan pekerjaan.

\section{KESIMPULAN}

1. Kesimpulan

Setelah melakukan penelitian dilapangan pada proyek peningktan jalan Alun-Alun Suka Makmue-Jalan Lingkar Timur Ibu Kota Tahap II Kabupaten Nagan Raya, dapat diambil beberapa kesimpulan adalah sebagai berikut :

a. Pengelolaan dan pemanfaatan alat berat yang baik dapat mempercepat target waktu yang diharapkan;

b. Jenis alat berat yang akan digunakan sangat berpengaruh terhadap proses pelaksanaan pekerjaan;

c. Keadaan cuaca yang baik juga mempengaruhi proses pelaksanaan pekerjaan selesai tepat pada waktunya;

d. Hasil perhitungan produktivitas alat berat didapatkan untuk dump truck $259,2 \mathrm{~m}^{3} / \mathrm{hari}$, motor grader $1026,43 \mathrm{~m}^{3} /$ hari, vibrator roller $518,4 \mathrm{~m}^{3} /$ hari, water tanker truck 129,6 $\mathrm{m}^{3} /$ hari;

e. Hasil perhitungan waktu pemakaian alat berat didapatkan untuk dump truck pada pekerjaan timbunan pilihan selama 11 hari, pekerjaan lapisan agregat kelas B selama 6 hari, pekerjaan lapisan agregat kelas A selama 4 hari, motor grader pada pekerjaan timbunan pilihan selama 3 hari, pekerjaan lapisan agregat kelas B selama 2 hari, pekerjaan lapisan agregat kelas A selama 1 hari, vibrator roller pada pekerjaan timbunan pilihan selama 6 hari, pekerjaan lapisan agregat kelas B selama 3 hari, pekerjaan lapisan agregat kelas A selama 2 hari, water tanker truck pada pekerjaan timbunan pilihan selama 21 hari, pekerjaan lapisan agregat kelas B selama 11 hari, pekerjaan lapisan agregat kelas A selama 8 hari. 


\section{Saran}

Adapun dalam penyusunan penelitian ini penulis dapat memaparkan beberapa saran adalah sebagai berikut :

a. Melakukan perawatan pada jalan yang dilalui oleh dump truck untuk lebih mempersingkat waktu.

b. Mengetahui kapan saatnya alat berat harus diganti untuk mencegah terjadinya hambatan pelaksanaan proyek.

c. Diharapkan ada penulisan lebih lanjut tentang analisis lain pada kondisi tanah pada pekerjaan pelebaran jalan.

\section{DAFTAR PUSTAKA}

[1] Ervianto, 2003, Manajemen Proyek Konstruksi, Yogyakarta.

[2] Rochmanhadi, 1982, Alat-alat Berat dan Penggunaannya, Departemen Pekerjaan Umum, Jakarta.

[3] Rochmanhadi, 1985, Perhitungan Biaya Pelaksanaan Pekerjaan, Departemen Pekerjaan Umum, Jakarta.

[4] Rostiyanti, 1999, Produktivitas Alat Berat Pada Proyek Konstruksi, Penerbit Rineka Cipta, Jakarta.

[5] Soedrajat, 1982, Efisiensi Penggunaan Alat Berat Pada Jalan Raya, Nova, Jakarta.

[6] Wilopo,D., 2011, Metode Konstruksi dan Alat-alat Berat, Fakultas Teknik Universitas Indonesia, Jakarta. 